Article

\title{
Antibiotic Treatment Prior to Injury Improves Post-Traumatic Osteoarthritis Outcomes in Mice
}

\author{
Melanie E. Mendez ${ }^{1}$, Deepa K. Murugesh ${ }^{1}$, Aimy Sebastian ${ }^{1}{ }^{\circledR}$, Nicholas R. Hum ${ }^{1,2}{ }^{\circledR}$, \\ Summer A. McCloy ${ }^{1}$, Edward A. Kuhn ${ }^{1}$, Blaine A. Christiansen ${ }^{3}$ and Gabriela G. Loots ${ }^{1,2, * \mathbb{D}}$ \\ 1 Lawrence Livermore National Laboratories, Physical and Life Sciences Directorate, \\ Livermore, CA 94550, USA; mendez20@llnl.gov (M.E.M.); murugesh2@llnl.gov (D.K.M.); \\ sebastian4@llnl.gov (A.S.); hum3@llnl.gov (N.R.H.); mccloy2@llnl.gov (S.A.M.); kuhn7@llnl.gov (E.A.K.) \\ 2 UC Merced, School of Natural Sciences, Merced, CA 95343, USA \\ 3 UC Davis Medical Center, Department of Orthopedic Surgery, Sacramento, CA 95817, USA; \\ bchristiansen@ucdavis.edu \\ * Correspondence: loots1@llnl.gov; Tel.: +1-925-423-0923
}

Received: 24 July 2020; Accepted: 29 August 2020; Published: 3 September 2020

check for

Abstract: Osteoarthritis (OA) is a painful and debilitating disease characterized by the chronic and progressive degradation of articular cartilage. Post-traumatic OA (PTOA) is a secondary form of OA that develops in $\sim 50 \%$ of cases of severe articular injury. Inflammation and re-occurring injury have been implicated as contributing to the progression of PTOA after the initial injury. However, there is very little known about external factors prior to injury that could affect the risk of PTOA development. To examine how the gut microbiome affects PTOA development we used a chronic antibiotic treatment regimen starting at weaning for six weeks prior to ACL rupture, in mice. A six-weeks post-injury histological examination showed more robust cartilage staining on the antibiotic $(A B)$-treated mice than the untreated controls $(\mathrm{VEH})$, suggesting slower disease progression in $\mathrm{AB}$ cohorts. Injured joints also showed an increase in the presence of anti-inflammatory M2 macrophages in the $\mathrm{AB}$ group. Molecularly, the phenotype correlated with a significantly lower expression of inflammatory genes Tlr5, Ccl8, Cxcl13, and Foxo6 in the injured joints of AB-treated animals. Our results indicate that a reduced state of inflammation at the time of injury and a lower expression of Wnt signaling modulatory protein, Rspo1, caused by AB treatment can slow down or improve PTOA outcomes.

Keywords: osteoarthritis; PTOA; gene expression; RNA-seq; cartilage degeneration; tibial compression; gut microbiome; antibiotics; LPS

\section{Introduction}

The individual microbial cells that constitute the human gut microbiome outnumber our cells by a factor of 10 [1]. In utero, most fetuses are free of microorganisms [2]; the first exposure babies have to microbes is during birth as they move through the birth canal, hence babies born in natural birth are inoculated with microorganisms by their mothers. The gut microbiome initiates with breast feeding and builds complexity as the baby's diet evolves from milk to other types of foods [3]. It reaches dynamic stability by the age of 3 , and while a person's gut biome is relatively stable, there are many genetic and environmental factors that influence its composition and dynamic change in each person [4]. The microorganisms living in our gut that do not cause harm, and may even have a beneficial contribution to human health, are called commensals. The gut microbiome composition can be disrupted by dietary changes, antibiotic treatment or pathogenic infections, and in reciprocal interactions changes to the composition and abundance of commensals could affect the entire system by producing unwarranted gastrointestinal and immune diseases [5-7]. 
Published literature suggests that the gut microbiome has an indirect effect on bone through changes to the immune system and inflammatory cytokines [8,9]. Commensals aid in immune-regulation by releasing microbial associated molecular patterns (MAMPs) such as lipopolysaccharides (LPSs) that bind and activate toll-like receptors (Tlr); LPSs have been shown to bind to Tlr4 [9-14]. This activation causes an inflammatory cascade that releases inflammatory cytokines and interferons which act as transcription factors to induce naïve immune cells to mature [15-17]. Studies have suggested that gut biome dysbiosis can promote aggressive bone destruction mediated by osteoclasts due to an increase in tumor necrosis factor alpha (TNF- $\alpha$ ) [18-20]. Furthermore, we have previously shown that elevated levels of LPSs negatively impact bone by promoting bone loss and accelerate post-traumatic osteoarthritis (PTOA) development. We also showed that LPS administration prior to injury elevates Tlr5/7/8 transcription in the joint $[10,21]$. TNF- $\alpha$ promotes osteoclastogenesis by increasing RANK-L expression in bone marrow cells and therefore elevating the number of osteoclast precursor cells [20,22-24].

In the context of PTOA, it has been shown that when the gut microbiome of obese mice is modified by supplementing oligofructose, OA phenotypes diminish, which correlates with a reduction in the levels of inflammation in the colon and cytokine levels circulating in the serum and present in the knee [25]. Cyclic compressive loading in mice on a high-fat diet have promoted more severe PTOA phenotypes than mice on a normal diet, while $\mathrm{Tlr} 5^{--}$mice treated with ampicillin and neomycin have shown improvement in the cartilage phenotype post injury [26]. Germ-free mice have also been shown to have a better OA outcome after destabilization of the medial meniscus, and modifications to the gut microbiome have improved PTOA phenotype in obese mice $[25,27,28]$. Tibial compression induced injury in 20-week-old germ-free mice has shown an increase in bone volume [29]. Therefore, a precedent exists in support of the gut microbiome composition as a potential risk factor for the development of PTOA, but additional studies are required to elucidate potential mechanisms that contribute to the unwarranted PTOA phenotypes.

Most PTOA-related studies to date have examined factors likely to exacerbate or accelerate the development of osteoarthritis post injury, if administered at the time of injury or shortly thereafter [30]. Since bone and cartilage sometimes exhibit an inverse relationship to insult, such that what is anabolic for bone is catabolic for cartilage and vice versa [31], we speculated that gut biome modifications would slow down or improve PTOA outcomes. Therefore, this study aimed to examine how partial elimination of the gut microbiome through antibiotic treatment prior to injury would influence PTOA outcomes. Studying the effects of medication administered before an injury is of high biomedical importance because, clinically, most concerns are centered on side-effects due to co-administration. Currently, however, standards of medical care do not consider gut biome status, nor is gut dysbiosis a recoded clinical parameter. Research that can show the prognostic and diagnostic value of gut biome status could potentially lead to new standards of care. In addition, antibiotics are widely prescribed to teens and young adults who may be active in sports and therefor more susceptible to joint injuries. According to the CDC, in 2016, 64.9 million oral antibiotic prescriptions were issued to people under the age of 20, the equivalent of 790 per 1000 people; therefore, gut dysbiosis may be more common than expected in young athletes suffering an articular injury [32]. As the population of the USA ages there will be an increase in PTOA cases; studying how antibiotics modify PTOA phenotypes will be helpful to finding preventative treatments in the future for both young and old patients.

\section{Results}

\subsection{Antibiotic Treatment Prior to Injury Delays Cartilage Resorption in Injured Joints}

Using an established, noninvasive, tibial compression PTOA mouse model [33-37], we examined whether a six-week course of antibiotics (ampicillin $(1.0 \mathrm{~g} / \mathrm{L}) /$ neomycin $(0.5 \mathrm{~g} / \mathrm{L}))$ [26] would impact OA outcomes, post injury. C57Bl/6J mice were examined histologically at six weeks post injury. Examination of the uninjured, contralateral femoral heads revealed a more intense Safranin-O staining 
throughout the articular cartilage of the antibiotic (AB)-treated group compared to untreated controls (VEH), but both $\mathrm{AB}$ and VEH joints displayed normal morphology (Figure 1A,C). A slightly less mineralized area, characterized by large pockets of bone marrow, was observed in the femoral condyle of $A B$-treated, injured joints, relative to the VEH injured group (Figure 1B,D). Consistent with the AB uninjured control, the femoral condyle of the injured $A B$ group (Figure 1d; arrow, asterisk) appeared to also have an increase in Safranin-O staining intensity as well as a thicker articular cartilage layer than the injured VEH, suggesting higher levels of proteoglycans and reduced chondrocyte apoptosis in the injured joints of AB-treated animals (Figure 1b; arrow, asterisk). The meniscus (Figure 1bb,dd; arrow, asterisk) of injured $A B$ joints showed a thicker hyperplastic morphology with enhanced cellular infiltration. The meniscus in the injured VEH group also showed cellular infiltration but at a significantly lower level than the $A B$ injured group. Examination of the sagittal views of the joints by a modified Osteoarthritis Research Society International (OARSI) grading scale determined that AB-treated injured joints had a significantly lower cartilage score than VEH-treated injured joints with a $p$-value of 0.038 (Figure 1E). These results imply that modifying the gut microbiome through the administration of an ampicillin/neomycin antibiotic cocktail prior to injury was sufficient to improve the cartilage phenotype subsequent to trauma, and reduce PTOA outcomes.
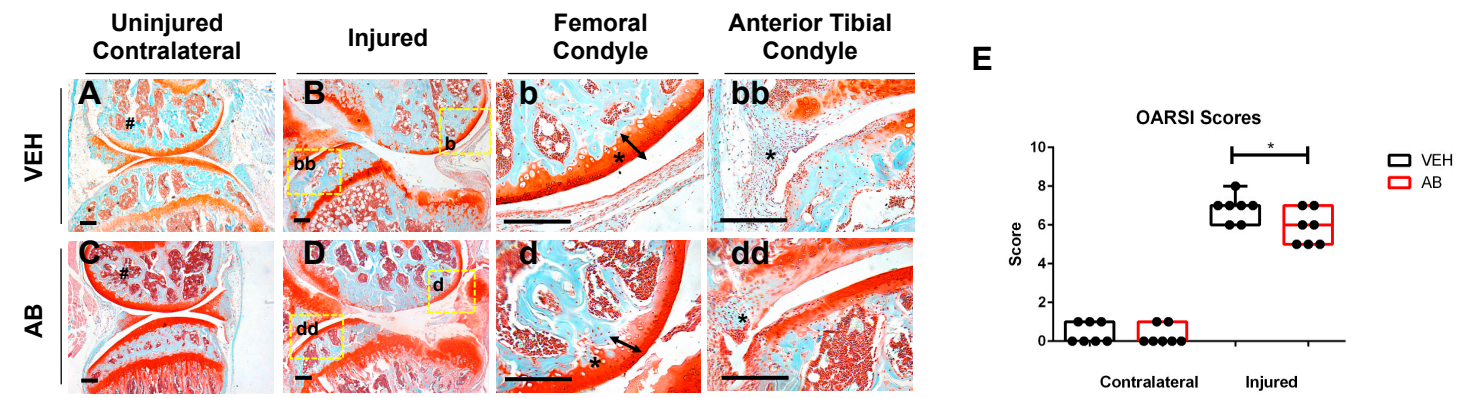

Figure 1. Characterization of post traumatic osteoarthritis (PTOA)-associated structural changes of antibiotic-treated animals in the knee. (A) Histological evaluation of vehicle (VEH) contralateral, (B-bb) VEH injured, (C) Antibiotic treated (AB) contralateral, and (D-dd) AB injured joints conducted at six weeks post injury using Safranin-O and Fast Green staining (scale bars indicate $200 \mathrm{~mm}$ ). High magnification images corresponding to yellow boxes $(\mathbf{B}, \mathbf{D})$ are provided b, bb, d, dd. (E) PTOA severity was quantified using a modified OARSI scoring system (* $p$-value $<0.05)$.

\subsection{Antibiotic Treatment Has a Negative Effect on Bone, Post Injury}

The bone phenotypes of AB- and VEH-treated mice were characterized by micro-computed tomography $(\mu \mathrm{CT})$ to quantify subchondral trabecular bone mass and osteophyte volume at six weeks post injury. Consistent with prior published results, VEH injured joints had significantly less subchondral bone volume (BV/TV) by $\sim 17.28 \%$ and $\sim 11.31 \%$ when compared to contralateral and uninjured controls, respectively (Figure 2A). Antibiotic-treated injured joints lost $13.67 \%$ when compared to contralateral $\mathrm{AB}$ treated and $17.42 \%$ when compared to uninjured $\mathrm{AB}$-treated controls. The subchondral bone volume (BV/TV) fraction of $\mathrm{AB}$ group had $\sim 0.2 \%, \sim 7.1 \%$, and $\sim 10.9 \%$ lower $\mathrm{BV} / \mathrm{TV}$ than the VEH group when comparing the uninjured, injured, and contralateral groups; the contralateral group was the only one that was statistically significant, suggesting that $A B$ treatment does not elevate BV/TV in the uninjured leg (Figure 2A). Trabecular number (Tb.N) of the AB group had $\sim 0.2 \%$ and $\sim 0.4 \%$ higher Tb.N on the uninjured and injured groups, respectively, compared to the VEH; the contralateral had $\sim 1.1 \%$ lower Tb.N on the VEH. Tb.N was not statistically significant (Figure 2B). Trabecular thickness (Tb.Th) showed the VEH group had $\sim 2.9 \%, \sim 7.6 \%$, and $\sim 10.6$ higher Tb.Th than uninjured, injured, and contralateral $\mathrm{AB}$ cohorts; injured and contralateral were significant (Figure 2C). Trabecular spacing (Tb.Sp) AB showed $\sim 1 \%, \sim 0.4 \%$, and $\sim 2.2 \%$ larger $\mathrm{Tb} . \mathrm{Sp}$ than the VEH uninjured, injured, and contralateral groups, respectively; none were statistically significant (Figure 2D). The VEH group had $\sim 39.7 \%$ significantly higher osteophyte volume (Op.V) compared to 
the AB cohort (Figure 2E). Visual representations of Op.V showed a larger amount of osteophytes in VEH joints, consistent with the quantification data (Figure 2F).

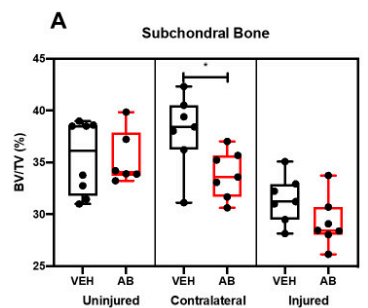

E

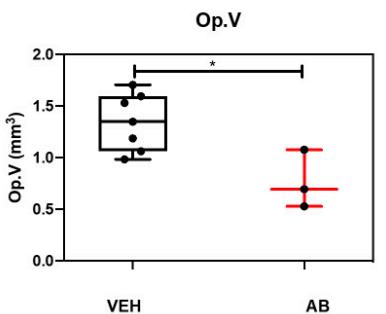

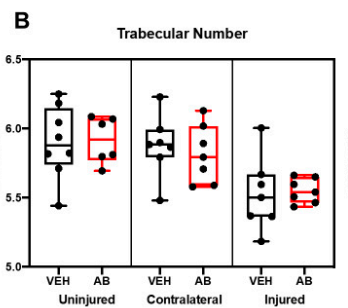

$\mathbf{F}$

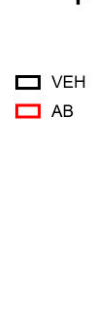

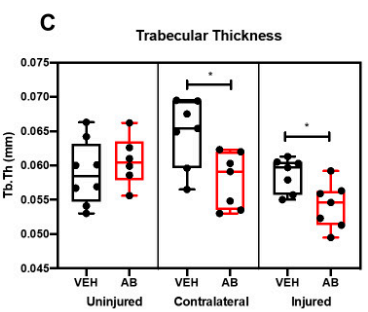

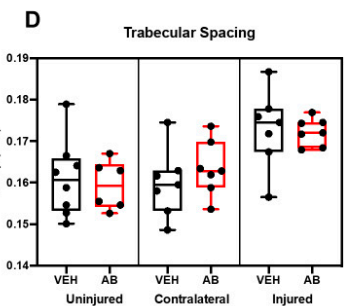

Osteophyte Images

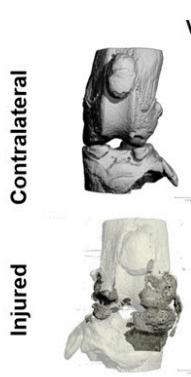

VEH

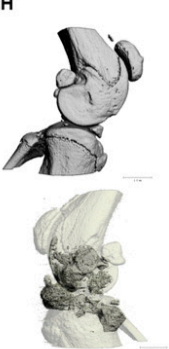

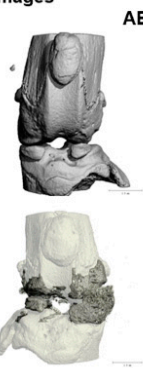

$A B$

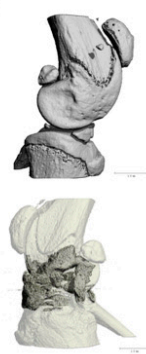

Figure 2. Bone phenotype of antibiotic-treated injured mice. (A) Subchondral trabecular bone volume fraction (BV/TV) of the distal femoral epiphysis. (B) Trabecular number was measured using the average number of trabeculae per unit length. (C) Trabecular thickness was measured using the mean thickness of trabeculae assessed using direct 3D methods. (D) Trabecular spacing was measured using the mean distance between trabeculae, assessed using direct 3D methods [38]. (E) Osteophyte volume at six weeks post injury. (F) Osteophyte imaging using $\mu \mathrm{CT}$. $\left({ }^{*} p<0.05\right)$.

\subsection{LPS Treatment Compared to AB Treatment}

Lipopolysaccharides (LPSs) administered five days prior to the joint injury did not elicit any significant changes in the bone phenotype when compared to the AB-treated uninjured bones. However, as previously reported [10], LPS administration alone was sufficient to modulate the cartilage phenotype on both the contralateral and injured joints towards a more severe phenotype (Figure 3E,F). LPS injured joints showed an enhanced thinning of the femoral cartilage that was distinguishable from the cartilage of the VEH and AB injured groups (Figure $3 b, d, f)$. The damage to the cartilage in the LPS injured joints corresponded with a significantly higher OARSI score than the VEH and AB injured joints (Figure 3I). There was an increase in cellular infiltration on the AB- and LPS-treated joints compared to the VEH (Figure 3bb,dd,ff). Combination of the AB treatment and LPS challenge (AB+LPS) significantly improved the LPS-mediated phenotype, reverting the contralaterals back to the OARSI scores recorded for the VEH injured and uninjured groups (Figure 3A,B,G,H). These results indicate that the effects of LPSs are blunted by the AB treatment, where statistical analysis does not distinguish between VEH and $A B+L P S$ in either the uninjured or injured groups (Figure 3I). 


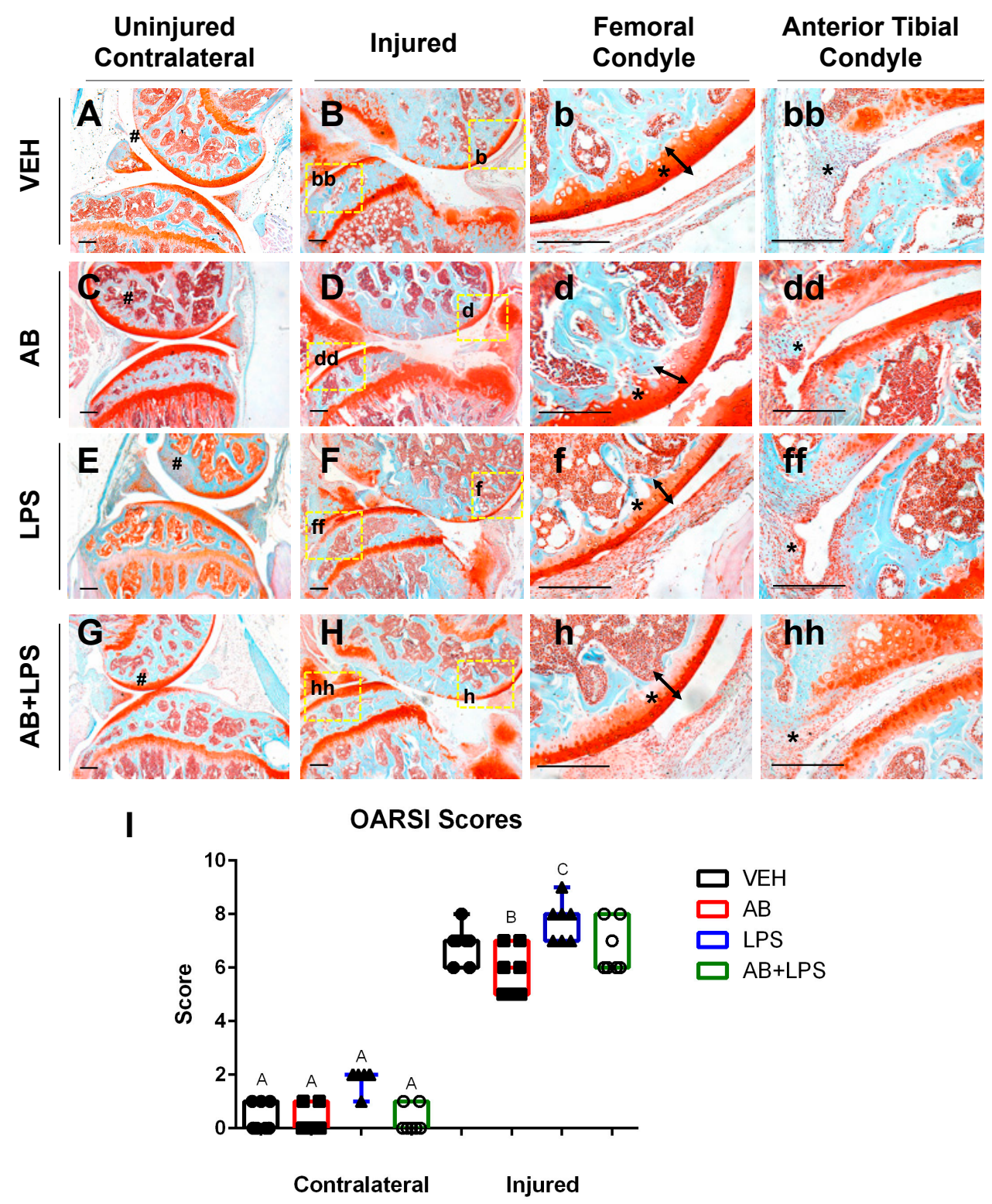

Figure 3. Characterization of PTOA-associated structural changes in the injured VEH, AB, LPS, and AB+LPS groups. (A-hh) Histological evaluation of uninjured and injured joints at six weeks post injury using Safranin-O and Fast Green staining. Black scale bars indicate $200 \mu \mathrm{m}$. Numeral sign indicates the femoral condyle (A,C,E,G). High magnification images corresponding to yellow boxes $(\mathbf{B}, \mathbf{D}, \mathbf{F}, \mathbf{H})$ are provided $(\mathbf{b}, \mathbf{b b}, \mathbf{d}, \mathbf{d d}, \mathbf{f}, \mathbf{f f}, \mathbf{h}, \mathbf{h h})$. Arrows and asterisks indicate the thickness of the cartilage in the femoral condyle $(\mathbf{b}, \mathbf{d}, \mathbf{f}, \mathbf{h})$. Asterisks indicate cellularity in the synovium (bb, dd, ff, hh). (I) OARSI scores $\left({ }^{*} p\right.$-value $\left.<0.05\right)$.

Macrophages Associated with Healing Are Increased in Antibiotic-Treated Joints

Tissue resident macrophages are essential in providing innate immune defenses and regulating tissue and organ homeostasis [39]. Macrophages and other inflammatory cells are recruited to injury sites where they also play key roles in tissue remodeling and repair [40,41]. In the joint there is a population of inactive macrophages residing in the synovium [42]. These cells are activated under certain conditions such as injury or inflammation. Macrophages can be found using the marker F4/80, which is a marker for cells of mononuclear phagocyte lineage in mice [43]. Macrophages can be both pro-inflammatory (M1) and anti-inflammatory (M2), and the co-action of these subtypes can repair damaged tissue through specific cytokine secretion. Identification of both macrophage populations was 
done using F4/80 and iNOS as an M1 marker while using CD206 as a M2 marker. In the joint, however, a change in the M1/M2 ratio may be critical in PTOA progression and development. Histological examination of the injured joints indicated a hyperplastic synovium that appeared to have significant cellular infiltration on LPS- and AB-treated injured joints (Figure 3dd,ff; asterisk), and this morphology was similar to that of LPS-treated injured joints previously described [10]. To determine whether AB treatment prior to ACL rupture altered the composition of M1 and M2 cells in the injured joint, we used M1/M2 specific antibody markers to distinguish these subtypes by immunohistochemistry (Figure 4). On the meniscus, we observed a slightly higher staining of anti iNOS antibody indicative of some M1 macrophage infiltration in the AB injured joints compared to the VEH injured joints (Figure 4A,B). The M1 macrophage infiltration presence in AB injured joints was less than that of LPS injured joints (Figure 4B,C). In contrast, we observed a higher level of anti CD206 antibody staining in AB injured joints when compared to VEH and LPS injured, indicative of higher levels of M2 macrophages present in the injured joints of AB-treated animals (Figure 4D-F). These results suggest that while there is an increase in macrophages for both LPS and AB treatments, the LPS-treated joints have an increase in pro-inflammatory macrophages while AB-treated joints have an increase in anti-inflammatory macrophages that may be helping mitigate the PTOA phenotype.
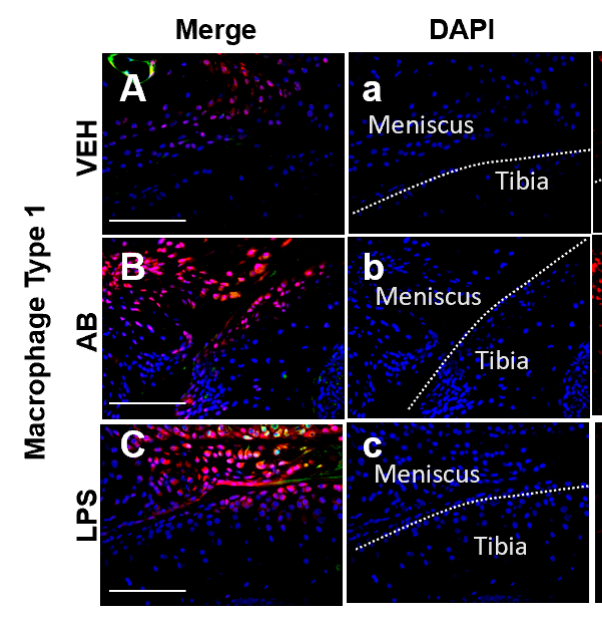

F4/80
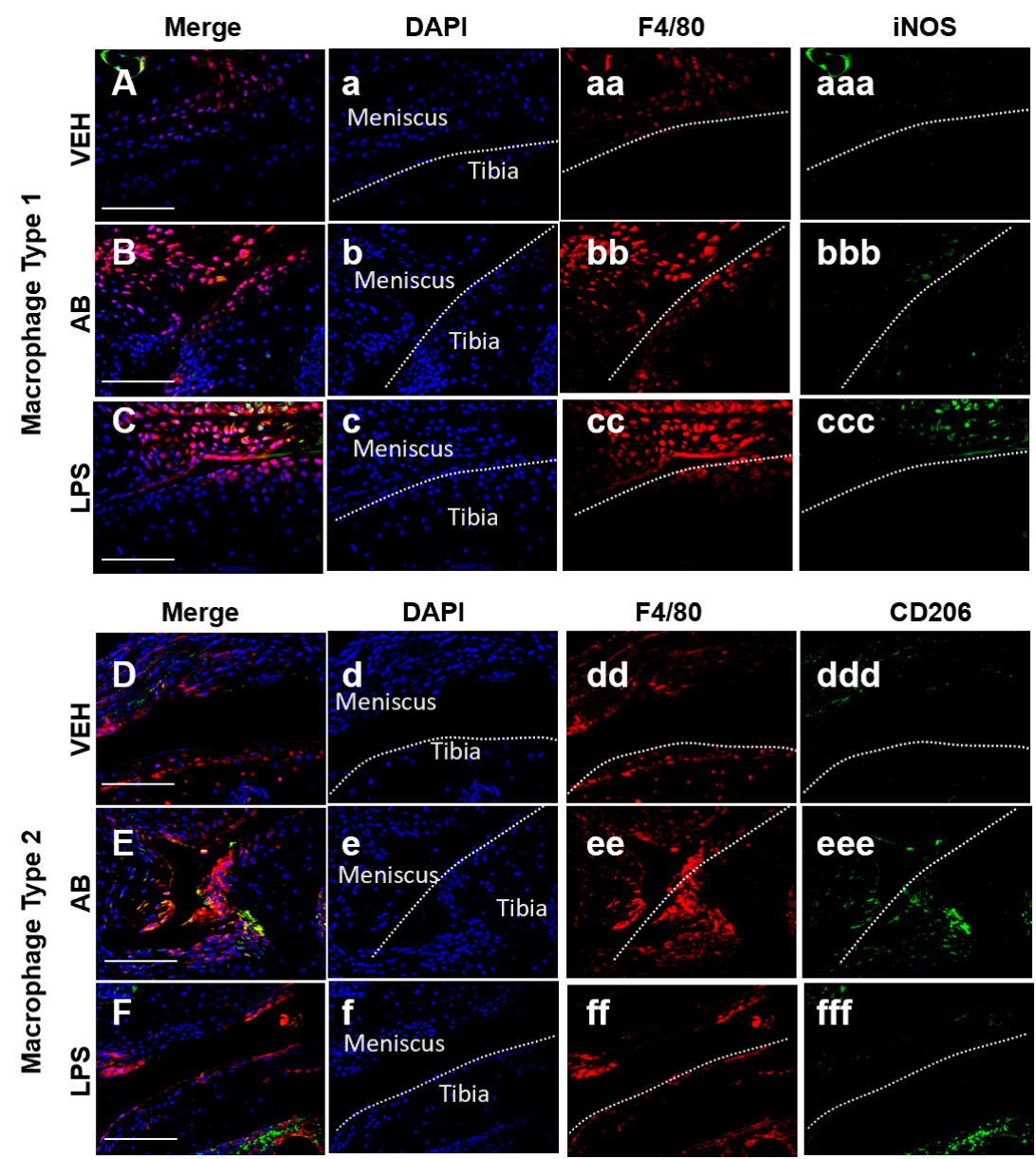

CD206
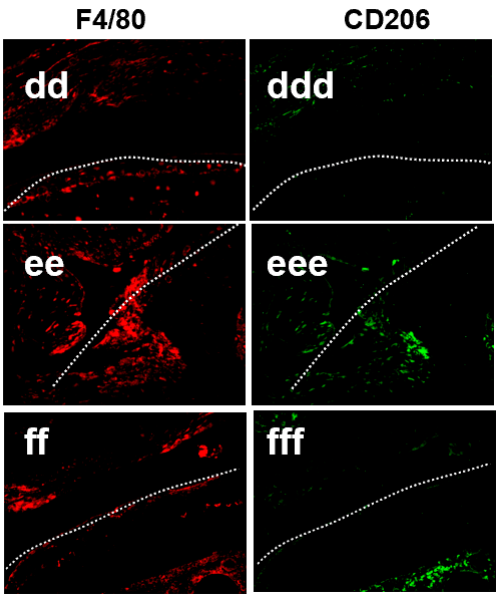

Figure 4. Macrophage infiltration analysis of the VEH-, AB-, and LPS-treated injured joints. (A-C) Fluorescent immunohistochemistry (IHC) of macrophage type 1 markers F4/80 and iNOS. (D-F) Fluorescent IHC of macrophage type 2 markers F4/80 and CD205. Dashed line in white represents the surface of the anterior tibial condyle for all images. (a-f) DAPI; (aa-ff) F4/80; (aaa-ccc) iNOS; (ddd-fff) CD206. White scale bar represents $100 \mu \mathrm{m}$. 


\subsection{Gene Expression Changes Associated with Chronic Antibiotic Treatment}

To determine antibiotic treatment-related molecular changes in knee joints we compared the transcriptome of 10-week-old mice that had been treated with $\mathrm{AB}$ in their drinking water to VEH controls. We found 620 significantly upregulated genes in uninjured AB compared to the uninjured VEH group; the majority of genes accounting for these transcriptional changes were associated with immune responses. Some of the groups we found were of genes associated with collagen (C1qb [44], and Fcna [45]), regulators of adaptive immunity (Btla [46], Lax1 [47], Tnfrsf13c [48], Lat [49], and Cd40 [50]), and genes associated with the major histocompatibility complex type II (Tnfrsf14 [51], Cd86 [52], and Cd8b1 [53]). We found 737 significantly downregulated genes in the AB uninjured group compared to the VEH uninjured group. These genes included regulators of skeletal development (Alpl [37], Col6a1 [54], Col6a2 [55], Sox9 [37], Sox11 [56], and Wnt9a [57]), Hippo signaling (Tead1, Tead4 [58], and Yap1 [59]), muscle contraction (Myh8, Myh2, and Myom2), and inflammatory response (Tlr5 [60], Ccl8 [61], Cxcl13 [37], C5ar1 [62], Cxcr1 [63], and Foxo6 [64]). Inflammatory gene comparison between $\mathrm{AB}$ injured and uninjured groups compared to the corresponding VEH groups are shown in Figure 5A and Table 1.

A

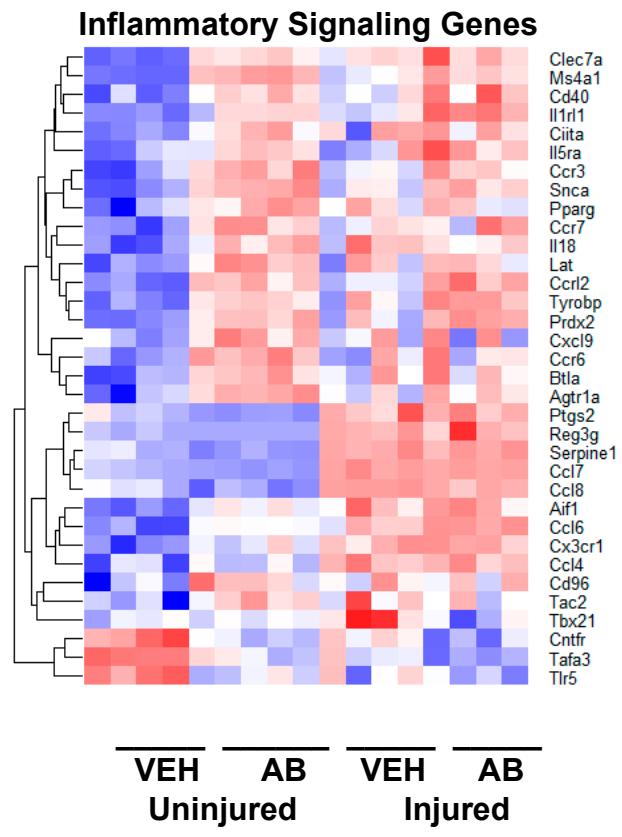

B

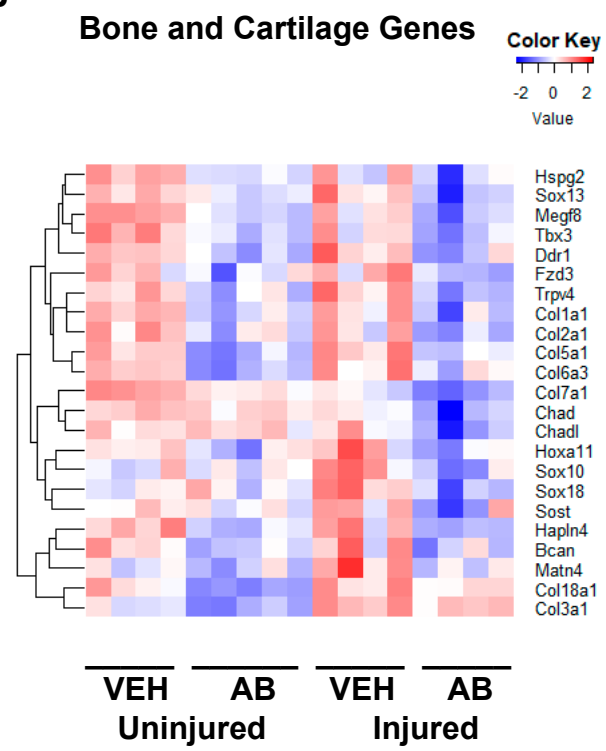

Figure 5. Gene expression changes associated with antibiotic treatment. (A) Genes associated with inflammatory process modified by $\mathrm{AB}$ treatment and $\mathrm{AB}$ with injury compared to VEH uninjured and injured. (B) Genes associated with bone and cartilage formation modified by AB treatment along with injury compared to VEH uninjured and injured. 
Table 1. Inflammatory gene overlap between the AB and VEH groups, showing the expression levels. Fold change ( $\log 2$ scale) values are shown in the table (FDR $<0.05$ for all genes). Changes that were not significant are denoted as ns.

\begin{tabular}{|c|c|c|}
\hline Gene & Uninjured & Injured \\
\hline Agtr1a & 0.898 & ns \\
\hline Aif1 & 0.740 & ns \\
\hline Btla & 0.880 & ns \\
\hline Ccl4 & 1.437 & ns \\
\hline Ccl6 & 0.679 & ns \\
\hline Ccl7 & -1.600 & ns \\
\hline Ccl8 & -0.790 & ns \\
\hline Ccr3 & 0.998 & ns \\
\hline Ccr6 & 1.522 & ns \\
\hline Ccr7 & 0.931 & ns \\
\hline Ccrl2 & 0.691 & ns \\
\hline$C d 40$ & 0.829 & ns \\
\hline$C d 96$ & 1.028 & ns \\
\hline Ciita & 1.033 & ns \\
\hline Clec $7 a$ & 0.863 & ns \\
\hline Cntfr & -1.117 & -0.870 \\
\hline$C \times 3 c r 1$ & 0.856 & ns \\
\hline Cxcl9 & 0.653 & $\mathrm{~ns}$ \\
\hline Il18 & 0.846 & ns \\
\hline Il1rl1 & 0.685 & 0.696 \\
\hline Il5ra & 0.762 & 0.719 \\
\hline Lat & 0.768 & ns \\
\hline Lat & 0.768 & ns \\
\hline Ms4a1 & 1.293 & ns \\
\hline Pparg & 0.665 & ns \\
\hline $\operatorname{Prdx2}$ & 0.905 & 0.607 \\
\hline Ptgs2 & -0.934 & ns \\
\hline $\operatorname{Reg} 3 g$ & -1.769 & $\mathrm{~ns}$ \\
\hline Serpine1 & -0.974 & ns \\
\hline Snca & 1.135 & ns \\
\hline Tac2 & 0.789 & ns \\
\hline Tafa3 & -1.234 & -0.905 \\
\hline$T b \times 21$ & ns & -0.913 \\
\hline Tlr5 & -0.987 & $\mathrm{~ns}$ \\
\hline Tyrobp & 0.645 & ns \\
\hline
\end{tabular}

We also found 185 genes significantly upregulated when comparing the AB injured to the VEH injured group. Among these we found negative regulators of cytokine production (Arg1 and Sars) and small molecule catabolic processes (Bad and Galk1). We found 284 genes significantly downregulated 
when comparing the $\mathrm{AB}$ injured group to the $\mathrm{VEH}$ injured group. Among these we found regulators of the Wnt signaling pathway (Sost [35,65], Fzd3), Notch signaling pathway (Notch4), collagen-associated genes (Chad, Col16a1, and Lep), and transcription factors known to be involved in cellular differentiation processes (Sox18, Foxd2, and Sox10). Genes associated with bone and cartilage formation are shown in Figure 5B and Table 2.

Table 2. Bone and cartilage gene overlap between the AB and VEH groups, showing expression levels. Fold change ( $\log 2$ scale) values are shown in the table (FDR $<0.05$ for all genes). Changes that were not significant are denoted as ns.

\begin{tabular}{|c|c|c|}
\hline Gene & Uninjured & Injured \\
\hline Bcan & -0.921 & -1.072 \\
\hline Chad & ns & -0.910 \\
\hline Chadl & ns & -0.617 \\
\hline Col18a1 & -0.923 & ns \\
\hline Col1a1 & -0.740 & -0.782 \\
\hline Col2a1 & -0.608 & -0.752 \\
\hline Col3a1 & -0.666 & ns \\
\hline Col5a1 & -0.800 & -0.660 \\
\hline Col6a3 & -1.055 & -0.598 \\
\hline Col7a1 & -0.689 & ns \\
\hline$D d r 1$ & ns & -0.603 \\
\hline$F z d 3$ & ns & -0.624 \\
\hline Hapln4 & -0.903 & -0.988 \\
\hline Hoxa11 & ns & -0.696 \\
\hline Hspg2 & -0.805 & -0.660 \\
\hline Matn4 & ns & -0.596 \\
\hline $\operatorname{Megf8}$ & -0.693 & -0.615 \\
\hline Sost & ns & -0.655 \\
\hline Sox10 & ns & -1.405 \\
\hline Sox13 & ns & -0.705 \\
\hline Sox18 & ns & -0.826 \\
\hline$T b x 3$ & -0.846 & -0.750 \\
\hline Trpo4 & ns & -0.627 \\
\hline
\end{tabular}

There were 78 genes upregulated in both $\mathrm{AB}$ groups when compared to their corresponding VEH control groups, including $C 1 q b$ [44] and $C d 3 d$ [66]. There were 151 genes downregulated in both $A B$ groups compared to the VEH group. These included skeletal muscle contraction (Myh1, Myh3 [67], Myh14 [68], and Myom3 [69]), and extracellular matrix proteins found in bone and cartilage (Col1a1, Col2a1, Col5a1, Col6a3 [37], and Col7a1 [70]). Tbx5 and Klhl40 were upregulated in the AB injured group and downregulated in the $\mathrm{AB}$ uninjured group when compared to their corresponding VEH groups. $C d 209 a$ and Rspo1 were downregulated in the $\mathrm{AB}$ injured group and upregulated in the $\mathrm{AB}$ uninjured group when compared to their corresponding VEH groups. Comparing the $A B$ uninjured and $A B$ injured groups showed that bone formation genes like Cthrc1 were upregulated in the AB injured group. Mmp3 [37], Lox, Loxl3, Mmp10, and Mmp19, were downregulated in the AB uninjured group when compared to the $\mathrm{AB}$ injured group. 
Comparison of Gene Expression Changes Between Chronic Antibiotic Treatment and LPS Treatment

In order to compare treatment-related molecular changes in the joint we compared the expression of $A B$ and LPS to VEH of the same injury. We found 32 genes that were upregulated in both the $\mathrm{AB}$ and LPS groups compared to the uninjured VEH group. Among these we found genes related to the inflammatory and immune system ( $\mathrm{Cx} 3 \mathrm{cr} 1, \mathrm{Cd} 3 \mathrm{~d}, \mathrm{Ccl}$, and $\mathrm{Ccl6})$. We found Rspo1 [71] to be upregulated in both the AB and LPS groups compared to the VEH groups, and downregulated in the $\mathrm{AB}$ injured group when compared to the injured VEH group. There were three genes ( $F g f b p 1$, Tnnc1, and Rab20) found to be upregulated in the injured AB and LPS groups compared to the injured VEH. We found 18 genes downregulated in the AB and LPS uninjured groups when compared to the corresponding VEH groups. Genes related to the immune system were among these (Bcl3, Prtn3, Tnfsf9, and Ifitm1). We found seven genes to be upregulated in the uninjured LPS group while downregulated in the uninjured $\mathrm{AB}$ group when compared to the corresponding VEH groups. These genes are Tlr5, C5ar1, Aqp4, Ryr3, Mdga1, Foxo6, and Kcng4. We found two genes (Cd209a and Lep) downregulated in both injured the AB and LPS groups compared to the injured vehicle. We found marker Cd209a, which is present in macrophages and dendritic cells, to be upregulated in the uninjured $A B$ and LPS groups and downregulated in the injured AB and LPS groups when compared to the corresponding VEH groups. Gene expression between the AB and LPS groups compared to the VEH groups is found in Table 3.

Table 3. Overlap of upregulated genes between the AB and LPS groups compared to the VEH showing the expression levels. Fold change ( $\log 2$ scale) values are shown in the table (FDR $<0.05$ for all genes). Changes that were not significant are denoted as ns.

\begin{tabular}{|c|c|c|c|c|}
\hline \multirow{2}{*}{ Gene } & \multicolumn{2}{|c|}{ VEH Uninjured } & \multicolumn{2}{|c|}{ VEH Injured } \\
\hline & AB Uninjured & LPS Uninjured & AB Injured & LPS Injured \\
\hline 4921531C22Rik & 0.680 & 0.945 & ns & ns \\
\hline Aldh3b2 & 1.289 & 0.963 & ns & ns \\
\hline Aldh3b3 & 0.783 & 1.204 & ns & ns \\
\hline Alox15 & 0.652 & 0.674 & ns & ns \\
\hline Arhgef3 & 0.592 & 0.602 & ns & ns \\
\hline Arl11 & 0.652 & 1.176 & ns & ns \\
\hline Ccl4 & 1.437 & 2.782 & ns & ns \\
\hline Ccl6 & 0.679 & 1.222 & ns & ns \\
\hline$C d 209 a$ & 1.336 & 0.901 & -0.592 & -0.669 \\
\hline$C d 3 d$ & 1.286 & 1.012 & 0.858 & ns \\
\hline$C d 84$ & 0.673 & 0.776 & ns & ns \\
\hline$C d 8 b 1$ & 1.480 & ns & ns & ns \\
\hline Clec7a & 0.863 & 1.204 & ns & ns \\
\hline Csta2 & 1.172 & 1.269 & ns & ns \\
\hline Cstdc4 & 1.338 & 1.411 & ns & ns \\
\hline$C \times 3 c r 1$ & 0.856 & 1.127 & ns & ns \\
\hline Cyp2ab1 & 1.010 & 1.803 & ns & ns \\
\hline
\end{tabular}


Table 3. Cont.

\begin{tabular}{|c|c|c|c|c|}
\hline \multirow{2}{*}{ Gene } & \multicolumn{2}{|c|}{ VEH Uninjured } & \multicolumn{2}{|c|}{ VEH Injured } \\
\hline & AB Uninjured & LPS Uninjured & AB Injured & LPS Injured \\
\hline$F g f b p 1$ & ns & ns & 1.518 & 1.753 \\
\hline Gzma & 1.587 & 1.392 & 0.610 & ns \\
\hline Jaml & 0.638 & 1.826 & ns & ns \\
\hline Klrc2 & 0.784 & 1.324 & ns & ns \\
\hline Lep & -0.701 & -0.682 & ns & ns \\
\hline$N 4 b p 2 l 1$ & 0.685 & 0.780 & ns & ns \\
\hline Nat8l & 0.729 & 1.402 & ns & ns \\
\hline Neurl3 & 0.782 & 0.984 & ns & ns \\
\hline$P 2 r x 2$ & 1.304 & 1.411 & ns & ns \\
\hline Ptpro & 0.780 & 1.169 & ns & ns \\
\hline Rab20 & ns & ns & 0.702 & 0.608 \\
\hline Rspo1 & 0.768 & 1.592 & -0.751 & ns \\
\hline Sirpb1a & 0.803 & 1.056 & ns & ns \\
\hline Sirpb1b & 0.667 & 1.096 & ns & ns \\
\hline Sirpb1c & 0.780 & 1.109 & ns & ns \\
\hline Skint3 & 0.922 & 1.670 & ns & ns \\
\hline Tmem 71 & 0.745 & 1.000 & ns & ns \\
\hline Tnnc1 & ns & ns & 0.881 & 0.780 \\
\hline Tyrobp & 0.645 & 0.695 & ns & ns \\
\hline Vnn3 & 0.941 & 1.210 & ns & ns \\
\hline
\end{tabular}

\section{Discussion}

The role of chronic antibiotic treatment prior to injury on the development of PTOA has not been previously investigated. Previous studies associating gut biome changes with skeletal phenotypes have focused primarily on bone, and have shown that the gut microbiome can influence osteoclastogenesis and affect bone volume [23]. Previous studies have also described the changes in the gut microbiome and bone using the same antibiotic cocktail [26,72]; however, our study is the first to examine how depletion of the gut biome with an ampicillin/neomycin antibiotics cocktail affects the development of osteoarthritis following a traumatic joint injury. Although morphologically our data indicate increased cellular infiltration in the synovium of injured joints of antibiotic-treated cohorts, reminiscent of synovitis induced by LPS administration [10], AB treatment did not have a significant effect on the BV/TV of the injured joint, resulting in no significant changes in BV/TV between the injured $\mathrm{VEH}$ and injured $\mathrm{AB}$ groups. The only significant bone phenotype was observed when contralateral were compared, where VEH-treated mice had an increase in BV/TV relative to uninjured control $\mathrm{AB}$-treated mice had a slight, but significant decrease in BV/TV. However, AB treatment improved the cartilage phenotype as reflected by a significantly lower OARSI score in these mice. There are several possible explanations for this outcome. The cellularity was examined using Ly6G and Ly6C markers, which highlighted an increase in the presence of monocytes, neutrophils, and granulocytes. In order to increase specificity, we stained with M1 and M2 markers, which showed an increase in the frequency of pro-inflammatory macrophages in the LPS-treated joints, while more anti-inflammatory macrophages were present in the AB-treated group. This correlation supports the conclusion that 
different macrophage subtypes could have influenced the exacerbation of PTOA in the LPS-treated cohorts, while deaccelerating PTOA progression in AB-treated cohorts.

It is also possible that chronic antibiotic treatment in juvenile mice (starting at four weeks of age) is anabolic to the articular cartilage, and during the six weeks of $A B$ treatment prior to the injury the cartilage of these animals produced significantly more extracellular matrix. Furthermore, the cartilage of AB-treated animals may also display slightly different biomechanical properties than VEH controls. This theory is in part supported by the observation that uninjured joints of AB-treated animals stained more intensely with Safranin-O than the VEH uninjured joints (Figure 1A,C). If the cartilage of AB-treated animals acquired different mechanical properties, including increased stiffness or increased elastic modulus, cartilage degradation in these mice may have proceeded at a slower pace than the VEH, accounting for the milder phenotype in these injured joints. Additionally, we see a downregulation of gene Rspo1 in injured AB joints when compared to injured VEH. This could be the reasoning for the decrease in OA progression, as Rspo1 has previously been shown to have a role during OA progression [71]. Future studies examining the biomechanical properties of cartilage at different ages and in different treatment groups will have to be conducted to confirm whether significant differences in these properties exist.

Alternatively, the observed PTOA outcomes may be driven primarily by molecular changes. We observed 113 genes, including inflammatory genes Bmper, Ccl2, Ccl7, Ccl8, Cxcl5, IL6, IL11, IL33, and Cxcl10, that overlapped between the injured VEH, LPS, and AB groups and the uninjured groups of their respective treatments with significantly elevated expression in the injured joints; however, the blunted effect was present only in the $\mathrm{AB}$ injured group, suggesting that these molecules have a less potent effect in when mice are treated with $\mathrm{AB}$ prior to injury. Gene expression data indicate that the inflammatory genes Ptgs2, Reg3g, and Serpine1 were downregulated in uninjured AB-treated mice, while $T b x 21$ was found to be downregulated in injured AB joints. Two inflammatory genes found to be downregulated in both the injured and uninjured $\mathrm{AB}$ groups as compared to the corresponding VEH were Tafa3 and Cntfr, which are both associated with the immune and nervous system. These genes have not been studied in the context of PTOA, and their influence on injury outcome would be interesting to study. When examining molecular changes in the immune system in prior reports, we have shown that elevated and persistent immune activation accelerates osteoarthritis phenotypes post injury [10]. Furthermore, we have shown that systemic LPS administration five days prior to injury negatively impacts PTOA, resulting in a more severe phonotype [10]. We have also shown that LPS-treated mice display highly elevated levels of toll-like receptors 5, 7, and 8 (Tlr5, Tlr7, Tlr8), and we hypothesized that the enhanced PTOA phenotype in LPS-treated mice may be due in part to increased signaling through these receptors. One complementary transcriptional result derived from the RNA-seq data examined herein is the discovery that Tlr 5 is significantly downregulated in AB-treated uninjured joints. Kim et al. showed that Tlr 5 in rheumatoid arthritis promotes monocyte presence and osteoclast formation due to the cross regulation of the Tlr 5 and TNF- $\alpha$ pathways [73]. If Tlr 5 similarly modulates the expression of inflammatory genes that are directly involved in cartilage degradation post injury, the observed transcriptional suppression of Tlr5 in uninjured joints may promote a molecular resistance to inflammatory cytokines. Future studies will have to evaluate whether Tlr5 receptor antagonists can prevent or slow down the development of OA post ACL rupture.

The current literature presents conflicting evidence on the effects of antibiotic treatment and the gut microbiome on bone, showing that modifications may have no significant changes in BV/TV after injury when compared to untreated control mice, but have a lowering effect when compared to uninjured treated mice [26]. In germ-free mice, AB treatment can increase the BV/TV after injury compared to injured controls, but these mice also have a lower BV/TV when compared to uninjured germ-free mice [29]. Our results showed no changes in BV/TV on injured AB-treated mice when compared to the injured $\mathrm{VEH}$, but did show a decrease in in $\mathrm{BV} / \mathrm{TV}$ when compared to the $\mathrm{AB}$ contralateral. These results are similar to the decrease in BV/TV observed after tibial compression (TC) injury in strains that are resistant to PTOA, like $M R L / M p J[36,74]$. Our AB group showed an improvement in 
cartilage, and though these mice are not OA-resistant to the extent of MRL/MpJ mice, we observed similarities in the expression of T-cell markers like $C d 3 d$ and $C d 8 b 1$ [36]. Although inflammation is resolved quicker in MRL/MpJ mice, bone resorption still occurs, similar to the C57Bl6 strain, due to the presence of pro-inflammatory cytokines and matrix metalloproteinases (MMPs) that promote osteoclastogenesis and extracellular matrix degradation [75-77]. The similarity of T-cell markers could potentially enhance healing and accelerate inflammation resolution in AB-treated mice, which could diminish the PTOA phenotype.

Our study uniquely examines the impact of long-term antibiotic treatment on OA outcomes subsequent to joint trauma. Prior to this study, we did not know if there were any PTOA changes caused by the administration of antibiotics. While we found that this particular AB regime had a beneficial effect on the health of injured and uninjured joints, it still remains to be elucidated whether short term $\mathrm{AB}$ treatment can be prophylactic; most importantly, questions remain about whether $\mathrm{AB}$ treatment post injury would have the same beneficial effect. This study highlights the importance of how the body works as a system and how systemic and local factors present prior to injury can significantly impact how our body heals and responds to trauma. This study highlights the importance of the gut biome in modulating PTOA, specifically by affecting toll-like receptors transcriptional levels that may in turn influence PTOA outcome after injury.

\section{Materials and Methods}

\subsection{Tibial Compression Overload}

C57Bl/6J mice were purchased from the Jackson Laboratory (Bar Harbor, ME, USA; Stock No: $000664)$ at four weeks of age and randomized into experimental groups $(n>=4)$. The antibiotic (AB) -treated group received treatment (ampicillin [78,79] (1.0g/L; Sigma; A9518-25G; St. Louis, MO, USA); neomycin [80-82] (0.5 g/L; Sigma; N1876-25G; St. Louis, MO, USA) in drinking water starting at weaning (four weeks of age) for six weeks; the untreated group (VEH) was provided with regular drinking water. Five days prior to injury at 10 weeks of age, cohorts of mice were separated into three groups (VEH, AB, and lipopolysaccharide (LPS)). The LPS group received an intraperitoneal (IP) injection of LPS ( $1 \mathrm{mg} / \mathrm{kg}$; Sigma; L6529-1MG; St. Louis, MO, USA), while the VEH and AB groups received an IP injection of saline of an equivalent volume. On the day of injury, all groups were subjected to non-invasive ACL rupture using a single dynamic tibial compressive overload using an electromagnetic material testing system (ElectroForce 3200, TA Instruments, New Castle, DE, USA) as previously described $[35,74,83]$. Cohorts were placed under anesthesia using isoflourane prior to injury [84]. ACL injury was performed by placing the mouse in the system and applying a compressive load at $1 \mathrm{~mm} / \mathrm{s}$ until ACL rupture (typically $12 \mathrm{~N}-14 \mathrm{~N}$ ); the uninjured group was placed in the system and received a non-injury compressive force $(2 \mathrm{~N}-3 \mathrm{~N})$. After injury, mice cohorts were given saline $(0.05 \mathrm{~mL})$ and buprenorphine $(0.05 \mathrm{mg} / \mathrm{kg})$ and returned to normal cage activity as previously described [34-36,74]. All animal experiments were approved by the Lawrence Livermore National Laboratory and University of California, Davis Institutional Animal Care and Use Committee (approved on 14/07/2016), and conformed to the Guide for the care and use of laboratory animals under protocol 250 .

\subsection{Micro-Computed Tomography $(\mu \mathrm{CT})$}

Injured joints, contralateral joints from injured mice, and bilateral joints from uninjured mice were collected six weeks post injury for all groups. Samples were dissected and fixed for $72 \mathrm{~h}$ at $4{ }^{\circ} \mathrm{C}$ using $10 \%$ neutral buffer formalin; samples were stored in $70 \%$ ethanol at $4{ }^{\circ} \mathrm{C}$ until scanned. Whole knees were scanned using a SCANO $\mu \mathrm{CT} 35$ (Bassersdorf, Switzerland) according to the rodent bone structure analysis guidelines (X-ray tube potential $=55 \mathrm{kVp}$, intensity $=114 \mathrm{~mA}, 10 \mu \mathrm{m}$ isotropic nominal voxel size, integration time $=900 \mathrm{~ms}$ ) [34]. Trabecular bone in the distal femoral epiphysis was analyzed by manually drawing contours on 2D transverse slides to designate the region of trabecular 
bone enclosed by the growth plate and subchondral cortical bone plate. We quantified trabecular bone volume fraction (BV/TV), trabecular thickness (Tb.Th), trabecular number (Tb.N), and trabecular separation (Tb.Sp) [38]. Mineralized osteophyte volume in injured and contralateral joints was also quantified by drawing contours around all heterotopic mineralized tissue attached to the distal femur and proximal tibia as well as the whole fabellae, menisci, and patella. Total mineralized osteophyte volume was then determined as the volumetric difference in mineralized tissue between injured and uninjured joints. Statistical analysis was performed using two-way ANOVA and a Student's $t$-test with a two-tailed distribution, with two-sample equal variance (homoscedastic test). For all tests, $p<0.05$ was considered statistically significant.

\subsection{Histological Assessment of Articular Cartilage and Joint Degeneration}

VEH-, AB-, and LPS-treated injured, contralateral, and uninjured joints were dissected six weeks post injury, then fixed, dehydrated, paraffin-embedded, and sectioned as previously described [74]. The cartilage was visualized in sagittal 6- $\mu \mathrm{m}$ paraffin serial using Safranin-O (0.1\%, Sigma; S8884; St. Louis, MO, USA) and Fast Green (0.05\%, Sigma; F7252; St. Louis, MO, USA) as previously described [35]. OA severity was evaluated using a modified Osteoarthritis Research Society International (OARSI) scoring scale as previously described [85]. Cartilage scoring began $\sim 0.4 \mathrm{~mm}$ out from the start of synovium to the articular cartilage. Blinded slides were evaluated by seven scientists (six with and one without expertise in OA) utilizing modified (sagittal) OARSI scoring parameters due to the severe phenotype caused by TC loading-destabilization that promotes mechanical-induced tibial degeneration on injured joints [74,85]. Modified scores: (0) for intact cartilage staining with strong red staining on the femoral condyle and tibia; (1) minor fibrillation without cartilage loss; (2) clefts below the superficial zone; (3) cartilage thinning on the femoral condyle and tibia; (4) lack of staining on the femoral condyle and tibia; (5) staining present on $90 \%$ of the entire femoral condyle with tibial degeneration; (6) staining present on over $80 \%$ of the femoral condyle with tibial degeneration; (7) staining present on $75 \%$ of the femoral condyle with tibial degeneration; (8) staining present on over $50 \%$ of the femora condyle with tibial degeneration; (9) staining present in $25 \%$ of the femoral condyle with tibial degeneration; (10) staining present in less than $10 \%$ of the femoral condyle with tibial degeneration.

\subsection{Immunofluorescent Staining}

Six-micrometer sections from injured samples from both treatment groups of $C 57 \mathrm{Bl} / 6 \mathrm{~J}$ were used. Unitrieve was used as an antigen retrieval method for $30 \mathrm{~min}$ at $65^{\circ} \mathrm{C}$ [86]. Primary antibodies: Anti-F4/80 (Abcam, ab16911(1:50)), Anti-CD206 (Abcam, ab64693(1:500)), and Anti-iNOS (Abcam, ab15323(1:100)) were used and incubated overnight at room temperature in a dark humid chamber. Negative control slides were incubated with secondary antibody only. Stained slides were mounted with Prolong Gold with DAPI (Molecular Probes, Eugene, OR, USA). Slides were imaged using a Leica DM5000 microscope. ImagePro Plus V7.0 Software and a QIClick CCD camera (QImaging, Surrey, BC, Canada) were used for imaging and photo editing.

\subsection{RNA Sequencing and Data Analysis}

C57Bl/6J injured and uninjured joints from VEH-, AB-, and LPS-treated male and female mice were collected $24 \mathrm{~h}$ after injury $(n>=4)$. Joints were dissected and cut at the edges of the joint region with small traces of soft tissue to preserve the articular integrity. RNA was isolated and sequenced as previously described [36]. RNA-seq data quality was checked using FastQC software (version 0.11.5). Sequence reads were aligned to the mouse reference genome (mm10) using STAR (version 2.6). After read mapping, 'featureCounts' from Rsubread package (version 1.30.5) was used to perform read summarization to generate gene-wise read counts. Differentially expressed genes (DEGs) were identified using edgeR (version 3.22.3). Genes with a false discovery rate (FDR) corrected $p$-value less than 0.05 and fold change greater than 1.5 were considered as DEGs. Heatmaps were generated using heatmap. 2 function in R package 'gplots'. 


\section{Conclusions}

Chronic antibiotic administration known to deplete some gram negative bacteria, primarily Bacteroidetes, while expanding the Proteobacteria phylum provided protective benefit from the development of post-traumatic osteoarthritis after joint injury.

Author Contributions: Study design: M.E.M. and G.G.L.; Data acquisition: M.E.M., D.K.M., N.R.H., S.A.M., E.A.K., and B.A.C. Data analysis and interpretation: M.E.M., A.S., B.A.C., and G.G.L., M.E.M. and G.G.L. wrote the manuscript. All authors have read and agreed to the published version of the manuscript.

Funding: M.E.M: D.K.M, A.S, N.R.H and G.G.L were supported by Lawrence Livermore National Laboratory LDRD grants 20-LW-002 and 16-ERD-007. G.G.L was also supported in part by DOD grant PR180268.

Acknowledgments: This work was performed under the auspices of the U.S. Department of Energy by Lawrence Livermore National Laboratory under Contract DE-AC52-07NA27344. LLNL-JRNL-812395.

Conflicts of Interest: The authors declare no conflict of interest.

\section{Abbreviations}

$\begin{array}{ll}\text { AB } & \text { Antibiotic group } \\ \text { ACL } & \text { Anterior cruciate ligament } \\ \text { BV.TV } & \text { Subchondral bone volume } \\ \text { ECM } & \text { Extracellular matrix } \\ \text { LPS } & \text { Lipopolysaccharide group } \\ \text { MMP } & \text { Metalloproteinase } \\ \text { OA } & \text { Osteoarthritis } \\ \text { PTOA } & \text { Post-traumatic osteoarthritis } \\ \text { RNA-seq } & \text { RNA sequencing } \\ \text { Tb.N } & \text { Trabecular number } \\ \text { Tb.Sp } & \text { Trabecular spacing } \\ \text { Tb.Th } & \text { Trabecular thickness } \\ \text { TC } & \text { Tibial compression } \\ \mu C T & \text { Microcomputed tomography } \\ \text { VEH } & \text { Vehicle group }\end{array}$

\section{References}

1. Bull, M.J.; Plummer, N.T. Part 1: The Human Gut Microbiome in Health and Disease. Integr. Med. (Encinitas) 2014, 13, 17-22. [PubMed]

2. Sender, R.; Fuchs, S.; Milo, R. Revised Estimates for the Number of Human and Bacteria Cells in the Body. PLoS Biol. 2016, 14, e1002533. [CrossRef] [PubMed]

3. Van den Elsen, L.W.J.; Garssen, J.; Burcelin, R.; Verhasselt, V. Shaping the Gut Microbiota by Breastfeeding: The Gateway to Allergy Prevention? Front. Pediatr. 2019, 7, 47. [CrossRef]

4. Tanaka, M.; Nakayama, J. Development of the gut microbiota in infancy and its impact on health in later life. Allergol. Int. 2017, 66, 515-522. [CrossRef] [PubMed]

5. Clemente, J.C.; Ursell, L.K.; Parfrey, L.W.; Knight, R. The impact of the gut microbiota on human health: An integrative view. Cell 2012, 148, 1258-1270. [CrossRef] [PubMed]

6. Liang, D.; Leung, R.K.-K.; Guan, W.; Au, W.W. Involvement of gut microbiome in human health and disease: Brief overview, knowledge gaps and research opportunities. Gut Pathog. 2018, 10, 3. [CrossRef]

7. Mohajeri, M.H.; Brummer, R.J.M.; Rastall, R.A.; Weersma, R.K.; Harmsen, H.J.M.; Faas, M.; Eggersdorfer, M. The role of the microbiome for human health: From basic science to clinical applications. Eur. J. Nutr. 2018, 57, 1-14. [CrossRef]

8. McAleer, J.P.; Vella, A.T. Understanding how lipopolysaccharide impacts CD4 T-cell immunity. Crit. Rev. Immunol. 2008, 28, 281-299.

9. Bahar, B.; O'Doherty, J.V.; Vigors, S.; Sweeney, T. Activation of inflammatory immune gene cascades by lipopolysaccharide (LPS) in the porcine colonic tissue ex-vivo model. Clin. Exp. Immunol. 2016, 186, $266-276$. [CrossRef] 
10. Mendez, M.E.; Sebastian, A.; Murugesh, D.K.; Hum, N.R.; McCool, J.L.; Hsia, A.W.; Christiansen, B.A.; Loots, G.G. LPS-induced Inflammation Prior to Injury Exacerbates the Development of Post-Traumatic Osteoarthritis in Mice. J. Bone Miner. Res. 2020. [CrossRef]

11. Soares, J.-B.; Pimentel-Nunes, P.; Roncon-Albuquerque, R.; Leite-Moreira, A. The role of lipopolysaccharide/ toll-like receptor 4 signaling in chronic liver diseases. Hepatol. Int. 2010, 4, 659-672. [CrossRef] [PubMed]

12. Calil, I.L.; Zarpelon, A.C.; Guerrero, A.T.G.; Alves-Filho, J.C.; Ferreira, S.H.; Cunha, F.Q.; Cunha, T.M.; Verri, W.A. Lipopolysaccharide induces inflammatory hyperalgesia triggering a TLR4/MyD88-dependent cytokine cascade in the mice paw. PLoS ONE 2014, 9, e90013. [CrossRef] [PubMed]

13. Mogensen, T.H. Pathogen recognition and inflammatory signaling in innate immune defenses. Clin. Microbiol. Rev. 2009, 22, 240-273. [CrossRef] [PubMed]

14. Maslanik, T.; Tannura, K.; Mahaffey, L.; Loughridge, A.B.; Beninson, L.; Benninson, L.; Ursell, L.; Greenwood, B.N.; Knight, R.; Fleshner, M. Commensal bacteria and MAMPs are necessary for stress-induced increases in IL-1 $\beta$ and IL-18 but not IL-6, IL-10 or MCP-1. PLoS ONE 2012, 7, e50636. [CrossRef] [PubMed]

15. Chen, Y.; Haines, C.J.; Gutcher, I.; Hochweller, K.; Blumenschein, W.M.; McClanahan, T.; Hämmerling, G.; Li, M.O.; Cua, D.J.; McGeachy, M.J. Foxp3(+) regulatory T cells promote T helper 17 cell development in vivo through regulation of interleukin-2. Immunity 2011, 34, 409-421. [CrossRef] [PubMed]

16. Chu, H.; Mazmanian, S.K. Innate immune recognition of the microbiota promotes host-microbial symbiosis. Nat. Immunol. 2013, 14, 668-675. [CrossRef] [PubMed]

17. Kim, C.H. Host and microbial factors in regulation of T cells in the intestine. Front. Immunol. 2013, 4, 141. [CrossRef]

18. Kitaura, H.; Kimura, K.; Ishida, M.; Kohara, H.; Yoshimatsu, M.; Takano-Yamamoto, T. Immunological Reaction in TNF- $\alpha$-Mediated Osteoclast Formation and Bone Resorption In Vitro and In Vivo. Clin. Dev. Immunol. 2013, 2013, 181849. [CrossRef]

19. McCabe, L.R.; Irwin, R.; Schaefer, L.; Britton, R.A. Probiotic use decreases intestinal inflammation and increases bone density in healthy male but not female mice. J. Cell. Physiol. 2013, 228, 1793-1798. [CrossRef]

20. Collins, F.L.; Schepper, J.D.; Rios-Arce, N.D.; Steury, M.D.; Kang, H.J.; Mallin, H.; Schoenherr, D.; Camfield, G.; Chishti, S.; McCabe, L.R.; et al. Immunology of Gut-Bone Signaling. Adv. Exp. Med. Biol. 2017, 1033, 59-94. [CrossRef]

21. Teramachi, J.; Inagaki, Y.; Shinohara, H.; Okamura, H.; Yang, D.; Ochiai, K.; Baba, R.; Morimoto, H.; Nagata, T.; Haneji, T. PKR regulates LPS-induced osteoclast formation and bone destruction in vitro and in vivo. Oral. Dis. 2017, 23, 181-188. [CrossRef] [PubMed]

22. Iqbal, J.; Yuen, T.; Sun, L.; Zaidi, M. From the gut to the strut: Where inflammation reigns, bone abstains. J. Clin. Investig. 2016, 126, 2045-2048. [CrossRef] [PubMed]

23. Charles, J.F.; Ermann, J.; Aliprantis, A.O. The intestinal microbiome and skeletal fitness: Connecting bugs and bones. Clin. Immunol. 2015, 159, 163-169. [CrossRef] [PubMed]

24. Schepper, J.D.; Collins, F.L.; Rios-Arce, N.D.; Raehtz, S.; Schaefer, L.; Gardinier, J.D.; Britton, R.A.; Parameswaran, N.; McCabe, L.R. Probiotic Lactobacillus reuteri Prevents Postantibiotic Bone Loss by Reducing Intestinal Dysbiosis and Preventing Barrier Disruption. J. Bone Miner. Res. 2019, 34, 681-698. [CrossRef] [PubMed]

25. Schott, E.M.; Farnsworth, C.W.; Grier, A.; Lillis, J.A.; Soniwala, S.; Dadourian, G.H.; Bell, R.D.; Doolittle, M.L.; Villani, D.A.; Awad, H.; et al. Targeting the gut microbiome to treat the osteoarthritis of obesity. JCI Insight 2018, 3. [CrossRef]

26. Guss, J.D.; Ziemian, S.N.; Luna, M.; Sandoval, T.N.; Holyoak, D.T.; Guisado, G.G.; Roubert, S.; Callahan, R.L.; Brito, I.L.; van der Meulen, M.C.H.; et al. The effects of metabolic syndrome, obesity, and the gut microbiome on load-induced osteoarthritis. Osteoarthr. Cartil. 2019, 27, 129-139. [CrossRef]

27. Ulici, V.; Kelley, K.L.; Azcarate-Peril, M.A.; Cleveland, R.J.; Sartor, R.B.; Schwartz, T.A.; Loeser, R.F. Osteoarthritis induced by destabilization of the medial meniscus is reduced in germ-free mice. Osteoarthr. Cartil. 2018, 26, 1098-1109. [CrossRef]

28. Szychlinska, M.A.; Di Rosa, M.; Castorina, A.; Mobasheri, A.; Musumeci, G. A correlation between intestinal microbiota dysbiosis and osteoarthritis. Heliyon 2019, 5, e01134. [CrossRef]

29. Hahn, A.K.; Wallace, C.W.; Welhaven, H.D.; Brooks, E.; McAlpine, M.; Christiansen, B.A.; Walk, S.T.; June, R.K. The microbiome mediates subchondral bone loss and metabolomic changes after acute joint trauma. bioRxiv 2020, 2020.05.08.084822. [CrossRef] 
30. Carbone, A.; Rodeo, S. Review of current understanding of post-traumatic osteoarthritis resulting from sports injuries. J. Orthop. Res. 2017, 35, 397-405. [CrossRef]

31. Hardcastle, S.A.; Dieppe, P.; Gregson, C.L.; Davey Smith, G.; Tobias, J.H. Osteoarthritis and bone mineral density: Are strong bones bad for joints? Bonekey Rep. 2015, 4, 624. [CrossRef] [PubMed]

32. Outpatient Antibiotic Prescriptions - United States, 2017; Center for Disease Control and Prevention: Atlanta, GA, USA, 2017.

33. Christiansen, B.A.; Anderson, M.J.; Lee, C.A.; Williams, J.C.; Yik, J.H.N.; Haudenschild, D.R. Musculoskeletal changes following non-invasive knee injury using a novel mouse model of post-traumatic osteoarthritis. Osteoarthr. Cartil. 2012, 20, 773-782. [CrossRef] [PubMed]

34. Lockwood, K.A.; Chu, B.T.; Anderson, M.J.; Haudenschild, D.R.; Christiansen, B.A. Comparison of loading rate-dependent injury modes in a murine model of post-traumatic osteoarthritis. J. Orthop. Res. 2014, 32, 79-88. [CrossRef] [PubMed]

35. Chang, J.C.; Christiansen, B.A.; Murugesh, D.K.; Sebastian, A.; Hum, N.R.; Collette, N.M.; Hatsell, S.; Economides, A.N.; Blanchette, C.D.; Loots, G.G. SOST/Sclerostin Improves Posttraumatic Osteoarthritis and Inhibits MMP2/3 Expression After Injury: SOST OVEREXPRESSION IMPROVES PTOA OUTCOMES. J. Bone Miner. Res. 2018, 33, 1105-1113. [CrossRef]

36. Sebastian, A.; Chang, J.C.; Mendez, M.E.; Murugesh, D.K.; Hatsell, S.; Economides, A.N.; Christiansen, B.A.; Loots, G.G. Comparative Transcriptomics Identifies Novel Genes and Pathways Involved in Post-Traumatic Osteoarthritis Development and Progression. Int. J. Mol. Sci. 2018, 19, 2657. [CrossRef] [PubMed]

37. Sebastian, A.; Murugesh, D.K.; Mendez, M.E.; Hum, N.R.; Rios-Arce, N.D.; McCool, J.L.; Christiansen, B.A.; Loots, G.G. Global Gene Expression Analysis Identifies Age-Related Differences in Knee Joint Transcriptome during the Development of Post-Traumatic Osteoarthritis in Mice. Int. J. Mol. Sci. 2020, 21, 364. [CrossRef]

38. Bouxsein, M.L.; Boyd, S.K.; Christiansen, B.A.; Guldberg, R.E.; Jepsen, K.J.; Müller, R. Guidelines for assessment of bone microstructure in rodents using micro-computed tomography. J. Bone Miner. Res. 2010, 25, 1468-1486. [CrossRef]

39. Klar, A.S.; Michalak-Mićka, K.; Biedermann, T.; Simmen-Meuli, C.; Reichmann, E.; Meuli, M. Characterization of M1 and M2 polarization of macrophages in vascularized human dermo-epidermal skin substitutes in vivo. Pediatr. Surg. Int. 2018, 34, 129-135. [CrossRef]

40. Fairweather, D.; Cihakova, D. Alternatively activated macrophages in infection and autoimmunity. J. Autoimmun. 2009, 33, 222-230. [CrossRef]

41. Wynn, T.A.; Barron, L.; Thompson, R.W.; Madala, S.K.; Wilson, M.S.; Cheever, A.W.; Ramalingam, T. Quantitative Assessment of Macrophage Functions in Repair and Fibrosis. In Current Protocols in Immunology; Coligan, J.E., Bierer, B.E., Margulies, D.H., Shevach, E.M., Strober, W., Eds.; John Wiley \& Sons, Inc.: Hoboken, NJ, USA, 2011; ISBN 978-0-471-14273-7.

42. Culemann, S.; Grüneboom, A.; Nicolás-Ávila, J.Á.; Weidner, D.; Lämmle, K.F.; Rothe, T.; Quintana, J.A.; Kirchner, P.; Krljanac, B.; Eberhardt, M.; et al. Locally renewing resident synovial macrophages provide a protective barrier for the joint. Nature 2019, 572, 670-675. [CrossRef]

43. Dos Anjos Cassado, A. F4/80 as a Major Macrophage Marker: The Case of the Peritoneum and Spleen. Results Prob. Cell Differ. 2017, 62, 161-179. [CrossRef]

44. Lubbers, R.; van Schaarenburg, R.A.; Kwekkeboom, J.C.; Levarht, E.W.N.; Bakker, A.M.; Mahdad, R.; Monteagudo, S.; Cherifi, C.; Lories, R.J.; Toes, R.E.M.; et al. Complement component C1q is produced by isolated articular chondrocytes. Osteoarthr. Cartil. 2020, 28, 675-684. [CrossRef] [PubMed]

45. Jarlhelt, I.; Genster, N.; Kirketerp-Møller, N.; Skjoedt, M.-O.; Garred, P. The ficolin response to LPS challenge in mice. Mol. Immunol. 2019, 108, 121-127. [CrossRef] [PubMed]

46. Lin, S.-C.; Kuo, C.-C.; Chan, C.-H. Association of a BTLA gene polymorphism with the risk of rheumatoid arthritis. J. Biomed. Sci. 2006, 13, 853-860. [CrossRef] [PubMed]

47. Wang, X.; Ning, Y.; Guo, X. Integrative meta-analysis of differentially expressed genes in osteoarthritis using microarray technology. Mol. Med. Rep. 2015, 12, 3439-3445. [CrossRef]

48. Smulski, C.R.; Eibel, H. BAFF and BAFF-Receptor in B Cell Selection and Survival. Front. Immunol. 2018, 9, 2285. [CrossRef]

49. Bacchelli, C.; Moretti, F.A.; Carmo, M.; Adams, S.; Stanescu, H.C.; Pearce, K.; Madkaikar, M.; Gilmour, K.C.; Nicholas, A.K.; Woods, C.G.; et al. Mutations in linker for activation of T cells (LAT) lead to a novel form of severe combined immunodeficiency. J. Allergy Clin. Immunol. 2017, 139, 634-642.e5. [CrossRef] 
50. Gotoh, H.; Kawaguchi, Y.; Harigai, M.; Hara, M.; Saito, S.; Yamaguchi, T.; Shimada, K.; Kawamoto, M.; Tomatsu, T.; Kamatani, N. Increased CD40 expression on articular chondrocytes from patients with rheumatoid arthritis: Contribution to production of cytokines and matrix metalloproteinases. J. Rheumatol. 2004, 31, 1506-1512. [PubMed]

51. Perdigones, N.; Vigo, A.G.; Lamas, J.R.; Martínez, A.; Balsa, A.; Pascual-Salcedo, D.; de la Concha, E.G.; Fernández-Gutiérrez, B.; Urcelay, E. Evidence of epistasis between TNFRSF14 and TNFRSF6B polymorphisms in patients with rheumatoid arthritis. Arthritis Rheum. 2010, 62, 705-710. [CrossRef]

52. Liu, M.F.; Kohsaka, H.; Sakurai, H.; Azuma, M.; Okumura, K.; Saito, I.; Miyasaka, N. The presence of costimulatory molecules CD86 and CD28 in rheumatoid arthritis synovium. Arthritis Rheum. 1996, 39, 110-114. [CrossRef]

53. Gwon, S.-Y.; Rhee, K.-J.; Sung, H.J. Gene and Protein Expression Profiles in a Mouse Model of Collagen-Induced Arthritis. Int. J. Med. Sci. 2018, 15, 77-85. [CrossRef] [PubMed]

54. Alexopoulos, L.G.; Youn, I.; Bonaldo, P.; Guilak, F. Developmental and osteoarthritic changes in Col6a1-knockout mice: Biomechanics of type VI collagen in the cartilage pericellular matrix. Arthritis Rheum. 2009, 60, 771-779. [CrossRef] [PubMed]

55. Lv, M.; Zhou, Y.; Polson, S.W.; Wan, L.Q.; Wang, M.; Han, L.; Wang, L.; Lu, X.L. Identification of Chondrocyte Genes and Signaling Pathways in Response to Acute Joint Inflammation. Sci. Rep. 2019, 9, 93. [CrossRef] [PubMed]

56. Xu, S.; Yu, J.; Wang, Z.; Ni, C.; Xia, L.; Tang, T. SOX11 promotes osteoarthritis through induction of TNF- $\alpha$. Pathol. Res. Pract. 2019, 215, 152442. [CrossRef] [PubMed]

57. Teufel, S.; Köckemann, P.; König, U.; Hartmann, C. Loss of Wnt9a and Wnt4 causes degenerative joint alterations. Osteoarthr. Cartil. 2018, 26, S94-S95. [CrossRef]

58. Fu, L.; Hu, Y.; Song, M.; Liu, Z.; Zhang, W.; Yu, F.-X.; Wu, J.; Wang, S.; Izpisua Belmonte, J.C.; Chan, P.; et al. Up-regulation of FOXD1 by YAP alleviates senescence and osteoarthritis. PLoS Biol. 2019, 17, e3000201. [CrossRef]

59. Zhang, Q.; Fang, X.; Zhao, W.; Liang, Q. The transcriptional coactivator YAP1 is overexpressed in osteoarthritis and promotes its progression by interacting with Beclin-1. Gene 2019, 689, 210-219. [CrossRef]

60. Chamberlain, N.D.; Vila, O.M.; Volin, M.V.; Volkov, S.; Pope, R.M.; Swedler, W.; Mandelin, A.M.; Shahrara, S. TLR5, a novel and unidentified inflammatory mediator in rheumatoid arthritis that correlates with disease activity score and joint TNF- $\alpha$ levels. J. Immunol. 2012, 189, 475-483. [CrossRef]

61. Zhang, X.; Chen, L.; Dang, W.-Q.; Cao, M.-F.; Xiao, J.-F.; Lv, S.-Q.; Jiang, W.-J.; Yao, X.-H.; Lu, H.-M.; Miao, J.-Y.; et al. CCL8 secreted by tumor-associated macrophages promotes invasion and stemness of glioblastoma cells via ERK1/2 signaling. Lab. Investig. 2020, 100, 619-629. [CrossRef]

62. Mödinger, Y.; Rapp, A.; Pazmandi, J.; Vikman, A.; Holzmann, K.; Haffner-Luntzer, M.; Huber-Lang, M.; Ignatius, A. C5aR1 interacts with TLR2 in osteoblasts and stimulates the osteoclast-inducing chemokine CXCL10. J. Cell. Mol. Med. 2018, 22, 6002-6014. [CrossRef]

63. Ha, H.; Debnath, B.; Neamati, N. Role of the CXCL8-CXCR1/2 Axis in Cancer and Inflammatory Diseases. Theranostics 2017, 7, 1543-1588. [CrossRef] [PubMed]

64. Wang, R.; Zhang, S.; Previn, R.; Chen, D.; Jin, Y.; Zhou, G. Role of Forkhead Box O Transcription Factors in Oxidative Stress-Induced Chondrocyte Dysfunction: Possible Therapeutic Target for Osteoarthritis? Int. J. Mol. Sci. 2018, 19, 3794. [CrossRef] [PubMed]

65. Yee, C.S.; Manilay, J.O.; Chang, J.C.; Hum, N.R.; Murugesh, D.K.; Bajwa, J.; Mendez, M.E.; Economides, A.E.; Horan, D.J.; Robling, A.G.; et al. Conditional Deletion of Sost in MSC-Derived Lineages Identifies Specific Cell-Type Contributions to Bone Mass and B-Cell Development. J. Bone Miner. Res. 2018, 33, 1748-1759. [CrossRef] [PubMed]

66. Zhang, R.; Yang, X.; Wang, J.; Han, L.; Yang, A.; Zhang, J.; Zhang, D.; Li, B.; Li, Z.; Xiong, Y. Identification of potential biomarkers for differential diagnosis between rheumatoid arthritis and osteoarthritis via integrative genome-wide gene expression profiling analysis. Mol. Med. Rep. 2018. [CrossRef] [PubMed]

67. Weiss, A.; Leinwand, L.A. The mammalian myosin heavy chain gene family. Annu. Rev. Cell Dev. Biol. 1996, 12, 417-439. [CrossRef]

68. Rossi, A.C.; Mammucari, C.; Argentini, C.; Reggiani, C.; Schiaffino, S. Two novel/ancient myosins in mammalian skeletal muscles: MYH14/7b and MYH15 are expressed in extraocular muscles and muscle spindles. J. Physiol. (Lond.) 2010, 588, 353-364. [CrossRef] 
69. Arvanitidis, A.; Henriksen, K.; Karsdal, M.A.; Nedergaard, A. Neo-epitope Peptides as Biomarkers of Disease Progression for Muscular Dystrophies and Other Myopathies. J. Neuromuscul. Dis. 2016, 3, 333-346. [CrossRef]

70. Chou, C.-H.; Lee, C.-H.; Lu, L.-S.; Song, I.-W.; Chuang, H.-P.; Kuo, S.-Y.; Wu, J.-Y.; Chen, Y.-T.; Kraus, V.B.; $\mathrm{Wu}, \mathrm{C} . \mathrm{C}$.; et al. Direct assessment of articular cartilage and underlying subchondral bone reveals a progressive gene expression change in human osteoarthritic knees. Osteoarthr. Cartil. 2013, 21, 450-461. [CrossRef]

71. Lee, Y.H.; Sharma, A.R.; Jagga, S.; Lee, S.S.; Nam, J.S. Differential Expression Patterns of Rspondin Family and Leucine-Rich Repeat-Containing G-Protein Coupled Receptors in Chondrocytes and Osteoblasts. Cell J. 2021, 22, 437-449. [CrossRef]

72. Rios-Arce, N.D.; Schepper, J.D.; Dagenais, A.; Schaefer, L.; Daly-Seiler, C.S.; Gardinier, J.D.; Britton, R.A.; McCabe, L.R.; Parameswaran, N. Post-antibiotic gut dysbiosis-induced trabecular bone loss is dependent on lymphocytes. Bone 2020, 134, 115269. [CrossRef]

73. Kim, S.-J.; Chen, Z.; Chamberlain, N.D.; Essani, A.B.; Volin, M.V.; Amin, M.A.; Volkov, S.; Gravallese, E.M.; Arami, S.; Swedler, W.; et al. Ligation of TLR5 promotes myeloid cell infiltration and differentiation into mature osteoclasts in rheumatoid arthritis and experimental arthritis. J. Immunol. 2014, 193, 3902-3913. [CrossRef] [PubMed]

74. Chang, J.C.; Sebastian, A.; Murugesh, D.K.; Hatsell, S.; Economides, A.N.; Christiansen, B.A.; Loots, G.G. Global molecular changes in a tibial compression induced ACL rupture model of post-traumatic osteoarthritis: GLOBAL MOLECULAR CHANGES AFTER ACL INJURY. J. Orthop. Res. 2017, 35, 474-485. [CrossRef]

75. Paiva, K.B.S.; Granjeiro, J.M. Bone tissue remodeling and development: Focus on matrix metalloproteinase functions. Arch. Biochem. Biophys. 2014, 561, 74-87. [CrossRef] [PubMed]

76. Nakatani, T.; Chen, T.; Partridge, N.C. MMP-13 is one of the critical mediators of the effect of HDAC4 deletion on the skeleton. Bone 2016, 90, 142-151. [CrossRef] [PubMed]

77. Klein, T.; Bischoff, R. Physiology and pathophysiology of matrix metalloproteases. Amino Acids 2011, 41, 271-290. [CrossRef]

78. Kaushik, D.; Mohan, M.; Borade, D.M.; Swami, O.C. Ampicillin: Rise fall and resurgence. J. Clin. Diagn. Res. 2014, 8, ME01-ME03. [CrossRef]

79. Chudobova, D.; Dostalova, S.; Blazkova, I.; Michalek, P.; Ruttkay-Nedecky, B.; Sklenar, M.; Nejdl, L.; Kudr, J.; Gumulec, J.; Tmejova, K.; et al. Effect of ampicillin, streptomycin, penicillin and tetracycline on metal resistant and non-resistant Staphylococcus aureus. Int. J. Environ. Res. Public Health 2014, 11, 3233-3255. [CrossRef]

80. Waksman, S.A.; Lechevalier, H.A.; Harris, D.A. Neomycin-production and antibiotic properties. J. Clin. Investig. 1949, 28, 934-939. [CrossRef]

81. Masur, H.; Whelton, P.K.; Whelton, A. Neomycin toxicity revisited. Arch. Surg. 1976, 111, 822-825. [CrossRef]

82. Macdonald, R.H.; Beck, M. Neomycin: A review with particular reference to dermatological usage. Clin. Exp. Dermatol. 1983, 8, 249-258. [CrossRef]

83. Christiansen, B.A.; Guilak, F.; Lockwood, K.A.; Olson, S.A.; Pitsillides, A.A.; Sandell, L.J.; Silva, M.J.; van der Meulen, M.C.H.; Haudenschild, D.R. Non-invasive mouse models of post-traumatic osteoarthritis. Osteoarthr. Cartil. 2015, 23, 1627-1638. [CrossRef] [PubMed]

84. Prys-Roberts, C. Isoflurane. Br. J. Anaesth 1981, 53, 1243-1245. [CrossRef] [PubMed]

85. Glasson, S.S.; Chambers, M.G.; Van Den Berg, W.B.; Little, C.B. The OARSI histopathology initiativerecommendations for histological assessments of osteoarthritis in the mouse. Osteoarthr. Cartil. 2010, 18 (Suppl. 3), S17-S23. [CrossRef]

86. Yee, C.S.; Xie, L.; Hatsell, S.; Hum, N.; Murugesh, D.; Economides, A.N.; Loots, G.G.; Collette, N.M. Sclerostin antibody treatment improves fracture outcomes in a Type I diabetic mouse model. Bone 2016, 82, $122-134$. [CrossRef] [PubMed]

(C) 2020 by the authors. Licensee MDPI, Basel, Switzerland. This article is an open access article distributed under the terms and conditions of the Creative Commons Attribution (CC BY) license (http://creativecommons.org/licenses/by/4.0/). 